\title{
EFEITO DA TEMPERATURA E DO SUBSTRATO NA GERMINAÇÃO DE SEMENTES DE Caesalpinia ferrea Mart. ex Tul. (LEGUMINOSAE, CAESALPINOIDEAE) ${ }^{1}$
}

\author{
Juliana Domingues Lima², Cilene Chaves Almeida ${ }^{3}$, Vânia Andréa Valente Dantas ${ }^{3}$, Breno Marques da \\ Silva e Silva ${ }^{3}$ e Wilson da Silva Moraes ${ }^{4}$
}

\begin{abstract}
RESUMO - Caesalpinia ferrea Mart. ex Tul. é uma leguminosa arbórea tropical que ocorre na região amazônica, sendo muito utilizada como planta medicinal e na arborização e paisagismo urbanos. Para viabilizar a produção de mudas, determinaram-se a melhor temperatura e o melhor substrato para a germinação das sementes. Sementes recém-colhidas apresentaram teor médio de água de 7,46\%, porcentagem de germinação de 3,33\% e baixo ganho de água durante a embebição, mostrando dormência tegumentar. A escarificação mecânica com lixa ${ }^{\circ}$ 40 foi um método eficiente para superação da dormência, comprovado pela alta porcentagem de germinação e embebição de água em sementes escarificadas. A porcentagem de germinação dessas sementes foi influenciada pela temperatura, mas não pelo substrato. Com base no tempo médio de germinação, recomenda-se a temperatura de $30^{\circ} \mathrm{C}$ e areia como substrato para germinação mais rápida de sementes escarificadas.
\end{abstract}

Palavras-chave: Jucá, ecarificação e dormência.

\section{EFFECT OF TEMPERATURE AND SUBSTRATE ON SEED GERMINATION OF Caesalpinia ferrea Mart. ex Tul. (LEGUMINOSAE, CAESALPINOIDEAE)}

\begin{abstract}
Caesalpinia ferrea Mart. ex Tul. is a tropical legume tree occurring in the Amazon region, commonly used as medicine plant and in urban landscaping. To make seedling production feasible the best temperature and substrate for seed germination were determined. Recently harvested seeds present $7.46 \%$ mean moisture content, $3.33 \%$ germination percentage and lower moisture gain during soaking, showing tegument dormancy. Mechanical scarification with 40 grit sandpaper was proven an efficient method to overcome the dormancy, resulting in higher germination percentage and water imbibition in scarified seeds. The germination percentage of scarified seeds was influenced by temperature, but not by substrate. Based on the mean germination time, it is recommended the temperature of $30^{\circ} \mathrm{C}$ and sand like substrate for faster germination of scarified seeds.
\end{abstract}

Keywords: Jucá, scarification and dormancy.

\footnotetext{
${ }^{1}$ Recebido em 11.10.2004 e aceito para publicação em 05.04.2006.

${ }^{2}$ Campus Experimental de Registro/UNESP, Rua Tamekishi Takano, 5, Centro, 11900-000 Registro-SP.E-mail: <judlima@ registro.unesp.br>.

${ }^{3}$ Curso de Ciências Biológicas da UNIFAP, Rodovia JK, km 2, s/n, Bairro Zerão, 68900-000 Macapá-AP.

${ }^{4}$ Pólo Regional do Vale do Ribeira, Av. Wild José de Souza, 454, Centro, 11.900-000 Registro-SP.
} 


\section{INTRODUÇÃO}

Nos últimos anos, tem-se intensificado o interesse na propagação de espécies nativas, em razão da necessidade de recuperação de áreas degradadas e recomposição da paisagem. Entretanto, não há conhecimento suficiente para o manejo e análise das sementes da maioria dessas espécies, de modo a fornecer dados que possam caracterizar seus atributos físicos e fisiológicos. Há, também, necessidade de se obterem informações básicas sobre a germinação, cultivo e potencialidade dessas espécies, visando à sua utilização para os mais diversos fins (ARAÚJO NETO et al., 2003).

O processo de germinação inicia-se com a absorção de água pela semente e termina com o início do alongamento de eixo embrionário, podendo ser identificado pela protrusão da radícula do embrião (BEWLEY e BLACK, 1982).

A temperatura, juntamente com a umidade do substrato e a luz, são os principais fatores que influenciam a germinação de sementes (MAYER, 1986).

Para qualquer processo ou evento, há geralmente uma temperatura mínima, abaixo da qual sua velocidade é zero; uma faixa infra-ótima, na qual a velocidade aumenta com a temperatura; uma faixa supra-ótima onde a velocidade diminui com a temperatura; e uma temperatura máxima acima da qual o processo não ocorre (GARCIAHUIDOBRO etal., 1982a,b; PROBERT, 1993). Atemperatura ótima é aquela em que o processo ocorre em maior intensidade e velocidade (HORIBE e CARDOSO, 2001). De modo geral, a ação da temperatura sobre a germinação decorre de modificações na conformação e estrutura das moléculas, particularmente proteínas e lipídeos, envolvidas em reações químicas durante a germinação e na estrutura das membranas (BEWLEY e BLACK, 1994).

As sementes de diferentes espécies apresentam faixas distintas de temperatura para germinação, as quais caracterizam sua distribuição geográfica (RAMOS e VARELA, 2003) e são, também, indícios valiosos nos estudos ecofisiológicos e de sucessão vegetal (LABOURIAU e PACHECO, 1978; FIGLIOLIA et al., 1993).

A influência do substrato na germinação é decorrente de suas características, como estrutura, grau de aeração, capacidade de retenção de água e grau de infestação de patógenos, dentre outras, que podem variar de acordo com o tipo de material utilizado (POPINIGIS, 1977). O substrato deve manter proporção adequada entre conteúdo de água e aeração, não devendo ser umedecido em excesso para evitar que a película de água envolva completamente a semente, restringindo a entrada e absorção do oxigênio (VILLAGOMEZ et al., 1979). Assim, a escolha do substrato deve ser feita, levando-se em consideração o tamanho da semente, a exigência quanto ao suprimento de água e à sensibilidade ou não à luz e a facilidade que oferece para realização das contagens e avaliação das plântulas (BRASIL, 1992).

A espécie em estudo, Caesalpinia ferrea Mart ex Tul., vulgarmente conhecida como jucá ou pau-ferro, pertence à família Leguminosae-Caesalpinoidae, é de fácil reconhecimento por causa da presença de manchas claras no tronco, folíolos pequenos, flores amarelas, legumes lisos, duros e aromáticos (RIZZINI, 1995). Possui grande potencial medicinal e ornamental, e sua madeira é utilizada na construção civil e na carpintaria (LORENZI, 1992).

Considerando-se a importância da temperatura e do substrato na germinação, o objetivo deste trabalho foi estudar o efeito desses fatores na germinação de sementes de Caesalpinia ferrea.

\section{MATERIAL E MÉTODOS}

Sementes de jucá (Caesalpinia ferrea) foram extraídas de frutos coletados em árvores nativas, localizadas em Porto Grande, AP. Os frutos colhidos foram transferidos para o Laboratório de Sementes do Instituto de Pesquisas Científicas e Tecnológicas do Estado do Amapá (IEPA), localizado em Macapá, AP.

No laboratório, determinou-se o grau de umidade das sementes em estufa à $75^{\circ} \mathrm{C}$ até as amostras atingirem peso constante, sendo expresso com base úmida. Antes da instalação do teste de germinação, parte das sementes coletadas teve dormência tegumentar quebrada por meio de escarificação mecânica com lixa número 40 (SILVA e MATOS, 1991).

Nos dois grupos de sementes (escarificadas e nãoescarificadas), foi feita a pesagem inicial de quatro repetições de 50 sementes. A seguir, as sementes foram colocadas em água destilada à temperatura ambiente, sendo pesadas após $0 ; 0,5 ; 1 ; 2 ; 3 ; 4 ; 5 ; 6 ; 7 ; 8 ; 9$; $10 ; 11 ; 12 ; 24 ; 48 ;$ e 72 horas de embebição. Antes de cada pesagem, elas foram secadas em papel-absorvente e, posteriormente, recolocadas em água destilada. A 
partir dos valores das porcentagens consecutivas, calculou-se a porcentagem de ganho de água em relação ao peso inicial das sementes, a fim de se estabelecerem as curvas de embebição.

Posteriormente, montou-se um experimento no delineamento inteiramente casualizado em esquema fatorial $3 \times 4$, com três temperaturas $\left(25,30,35^{\circ} \mathrm{C}\right) \mathrm{e}$ quatro substratos (areia, vermiculita, plantmax ${ }^{\circledR}$ e papel), para estudar a germinação das sementes escarificadas. Os substratos foram distribuídos em caixas plásticas do tipo gerbox de $11 \times 11 \mathrm{~cm}$, sendo cada tratamento constituído de quatro repetições de 30 sementes.

A germinação das sementes foi avaliada diariamente, observando-se a emergência da radícula como critério de germinação (BEWLEY e BLACK, 1994). A partir de contagens diárias de sementes germinadas, fez-se o cálculo da porcentagem de germinação e do tempo médio de germinação $(\mathrm{t})$, conforme a seguinte equação:

$$
\mathrm{t}=\sum \frac{\text { niti }}{\sum} \text { ni }
$$

em que:

ni - número de sementes germinadas por dia; e

ti - tempo de incubação em dias.

Os dados de porcentagem de germinação foram transformados em arco-seno $\sqrt{x / 100}$ para a normalização de sua distribuição (BARTLETT, 1947), porém nas tabelas e gráficos foram apresentadas as médias originais. Para comparação das médias entre tratamentos, utilizouse o teste de Tukey 5\% de probabilidade (GOMES, 1982).

\section{RESULTADOS E DISCUSSÃO}

Sementes de Caesalpinia ferrea recém-coletadas apresentaram teor médio de água de $7,46 \%$ e porcentagem de germinação de 3,33\%. O teor médio de água obtido está de acordo com o relato de Bradbeer (1988), em que a maioria das sementes ortodoxas apresenta cerca de 5 a $20 \%$ de água com base em sua massa fresca.

Na Figura 1, observa-se que a baixa germinação das sementes foi devida ao baixo ganho de água durante a embebição, demonstrando que as sementes apresentaram dormência tegumentar. Nesse caso, a ruptura do tegumento faz-se necessária para que haja a absorção de água pela semente até um nível adequado de hidratação, reiniciando suas atividades metabólicas, dando, assim, início ao processo germinativo (MAYER e POLJAKOFF-MAYBER, 1989; ÁQUILA, 2003).

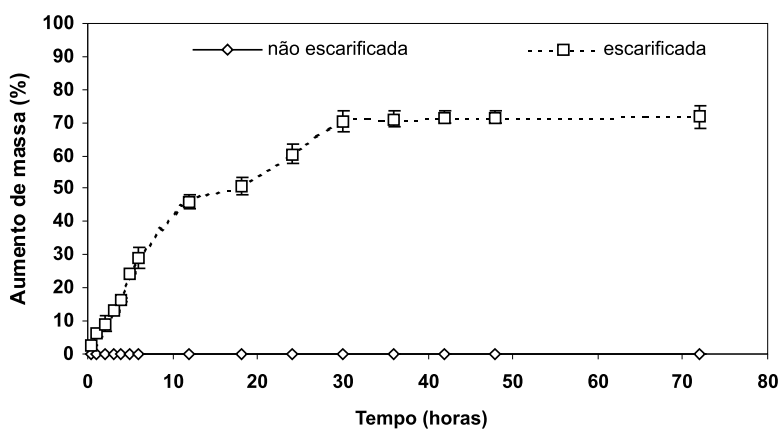

Figura 1 - Aumento de massa em relação à massa fresca inicial durante a embebição de sementes de Caesalpinia ferrea em água destilada.

Figure 1 - Increase in mass compared to initial fresh mass, during seed soaking of Caesalpinia ferrea in distilled water.

Em sementes escarificadas, a porcentagem de ganho de água foi alta durante as primeiras 24 horas do início da embebição, proporcionando aumento de massa de cerca de 70\% (Figura 1). Segundo Bewley e Black (1994), a embebição se inicia com o rápido ganho de água, seguido pela estabilização e pelos principais eventos metabólicos, e posteriormente, a semente volta a ganhar água como consequiência da germinação. Em sementes ortodoxas, o ganho de água durante a embebição atinge valores altos (BEWLEY e BLACK, 1994), que podem variar em outras espécies de 40 a $100 \%$ em relação ao peso inicial (GARCIA e DINIZ, 2003; CABRAL et al., 2003).

Em relação à porcentagem de germinação das sementes, não houve efeito significativo do substrato e da interação temperatura e substrato (Tabela 1). Não ocorreu diferença na porcentagem de germinação das sementes, nas temperaturas de 25 e $30^{\circ} \mathrm{C}$. Todavia, a $35^{\circ} \mathrm{C}$ houve uma tendência de queda na porcentagem de germinação, além de ter sido observado maior incidência de microrganismos nas sementes (Tabela 1).

Os resultados quanto à melhor temperatura para germinação estão de acordo com o proposto por Borges e Rena (1993), pois sementes de grande número de espécies florestais subtropicais e tropicais mostramse com potencial máximo de germinação na faixa de temperatura entre 20 e $30^{\circ} \mathrm{C}$. Segundo Ramos e Varela (2003), a temperatura ideal de germinação, geralmente, varia dentro da faixa de temperatura encontrada no local e na época ideal para a emergência e estabelecimento das plântulas.

R. Árvore, Viçosa-MG, v.30, n.4, p.513-518, 2006 
As porcentagens de germinação a 25 e $35^{\circ} \mathrm{C}$ foram, respectivamente, de 98,06 e $98,89 \%$, independentemente do substrato utilizado (Tabela 1). Entretanto, Nascimento e Oliveira (1999) verificaram porcentagem de germinação de apenas $26,5 \%$ a $28^{\circ} \mathrm{C}$ em sementes de jucá após a escarificação com lixa, considerando esse método pouco eficiente para a quebra de dormência.

Os substratos utilizados não afetaram as porcentagens de germinação das sementes, ou seja, foram estatisticamente iguais em todos os tratamentos. Não houve, também, interação entre a temperatura e o substrato quanto à porcentagem de germinação. A interação significativa entre temperatura e substrato quanto à porcentagem de germinação foi mencionada por Figliolia et al. (1993) e observada em Parkia discolor por Ramos e Varela (2003).

A temperatura afetou o tempo para a germinação das sementes, promovendo o menor tempo médio de germinação a $30^{\circ} \mathrm{C}$, seguida de 25 e $35^{\circ} \mathrm{C}$ (Tabela 2). $\mathrm{O}$ substrato areia promoveu o menor tempo médio de germinação, enquanto os demais substratos utilizados não apresentaram diferenças significativas com relação a essa variável (Tabela 2).

Dos substratos testados, o papel-filtro atingiu o maior tempo médio para a germinação das sementes a $30^{\circ} \mathrm{C}$, enquanto a $25^{\circ} \mathrm{C}$ não houve diferença nos tempos médios obtidos para a germinação tanto em papel-filtro quanto em vermiculita e plantmax ${ }^{\circledR}$. A 35 ${ }^{\circ} \mathrm{C}$ também não se observou diferença entre nenhum dos substratos utilizados (Tabela 2).

No estudo da interação temperatura e substrato, baseado no tempo médio de germinação, constatou-

Tabela 1 - Efeito da temperatura e do substrato na porcentagem de germinação de sementes ecarificadas de Caesalpinia ferrea

Table 1 - Effect of temperature and substrate on germination percentage of scarified seeds of Caesalpinia ferrea

\begin{tabular}{lcccc}
\hline Substrato & \multicolumn{3}{c}{ Temperatura $\left({ }^{\circ} \mathrm{C}\right)$} & Médias \\
\cline { 2 - 4 } & 25 & 30 & 35 & \\
\hline Papel & 97,78 & 96,67 & 96,67 & 97,04 \\
Areia & 98,89 & 100,00 & 96,67 & 98,52 \\
Vermiculita & 97,78 & 100,00 & 95,56 & 97,78 \\
Plantmax ${ }^{\circledR}$ & 97,78 & 98,89 & 96,77 & 97,81 \\
\hline Médias & $98,06 \mathrm{~b}$ & $98,89 \mathrm{a}$ & $96,42 \mathrm{~b}$ & \\
\hline
\end{tabular}

Médias seguidas da mesma letra minúscula na linha, não diferem entre si, a $5 \%$ de probabilidade, pelo teste de Tukey. se que, independentemente do substrato, a melhor temperatura para germinação foi de $30^{\circ} \mathrm{C}$. No entanto, independente da temperatura, o melhor substrato para germinação foi a areia (Tabela 2).

O fato de os substratos não afetarem a porcentagem de germinação das sementes pode indicar que as diferentes capacidades de retenção de água entre substratos provavelmente influenciaram a velocidade de embebição da semente e, por conseqüência, o tempo médio para germinação.

Tabela 2 - Efeito da temperatura e do substrato no tempo médio de germinação de sementes escarificadas de Caesalpinia ferrea

Table 2-Effect of temperature and substrate on the mean germination time of Caesalpinia ferrea scarified seeds

\begin{tabular}{lcccc}
\hline Substrato & \multicolumn{3}{c}{ Temperatura $\left({ }^{\circ} \mathrm{C}\right)$} & Médias \\
\cline { 2 - 4 } & 25 & 30 & 35 & \\
\hline Papel & $5,32 \mathrm{Ab}$ & $5,63 \mathrm{Ab}$ & $6,22 \mathrm{Aa}$ & $5,72 \mathrm{~A}$ \\
Areia & $4,52 \mathrm{Bb}$ & $3,50 \mathrm{Cc}$ & $5,42 \mathrm{Aa}$ & $4,48 \mathrm{~B}$ \\
Vermiculita & $5,53 \mathrm{Ab}$ & $4,76 \mathrm{Bc}$ & $6,14 \mathrm{Aa}$ & $5,47 \mathrm{~A}$ \\
Plantmaxâ & $5,73 \mathrm{Ab}$ & $4,11 \mathrm{Cc}$ & $6,49 \mathrm{Aa}$ & $5,44 \mathrm{~A}$ \\
\hline Médias & $5,27 \mathrm{~b}$ & $4,50 \mathrm{c}$ & $6,07 \mathrm{a}$ & \\
\hline
\end{tabular}

Médias seguidas da mesma letra maiúscula na coluna e da mesma letra minúscula na linha não diferem entre si, a $5 \%$ de probabilidade pelo teste de Tukey.

\section{CONCLUSÕES}

Os resultados deste estudo permitiram as seguintes conclusões com relação a Caesalpinia ferrea:

1) Sementes recém-coletadas apresentaram dormência imposta pela impermeabilidade do tegumento à água.

2) A escarificação mecânica do tegumento da semente com lixa foi um método eficiente para a superação da dormência, comprovado pela alta porcentagem de germinação e pela embebição em água após a escarificação da semente.

3) Em sementes escarificadas a porcentagem de germinação foi influenciada pela temperatura, mas não pelos substratos utilizados.

4) Com base no tempo médio de germinação, recomenda-se a temperatura de $30^{\circ} \mathrm{C}$ e areia como substrato para germinação mais rápida de sementes escarificadas. 


\section{REFERÊNCIAS BIBLIOGRÁFICAS}

ARAÚJO NETO, J. C.; AGUIAR, I. B.; FERREIRA, V. M. Efeito da temperatura e da luz na germinação de sementes de Acacia polyphylla DC. Revista Brasileira de Botânica, v. 26, n. 2, p. 249-256, 2003.

ÁQUILA, M. E. A. Fisiologia da germinação. In: JARDIM, M. A. G.; BASTOS, M. N. C.; SANTOS, J. U. M. (Ed.). Desafios da botânica no último milênio: inventário, sistematização e conservação da diversidade vegetal. Belém: MPEG, UFRA, EMBRAPA. 2003. 294 p.

BARTLETT, M. S. The use of transformations. Biometrics, v .3, p. 39-52, 1947.

BEWLEY, J. D.; BLACK, M. Physiology and biochemistry of seed in relation to germination: viability, dormancy and environmental control. Berlin: Springer-Verlag, 1982. $375 \mathrm{p}$.

BEWLEY, J. D.; BLACK, M. Seeds: physiology of development and germination. New York: Plenum Press, 1994. 445 p.

BORGES, E. E.; RENA, A. B. Germinação de sementes. In: AGUIAR, I. B.; PIÑA-RODRIGUES, F. C. M.; FIGLiOLIA, M. B. (Ed.). Sementes florestais tropicais. Brasília, DF: ABRATES, 1993. p.137-174.

BRADBEER, J. W. Seed dormancy and germination. Glasgow: Blackie Son. 1988. 146 p.

BRASIL. Ministério da Agricultura e Reforma Agrária. Regras para análise de sementes. Brasília, DF: SNDA/DNDV/CLAV, 1992. $365 \mathrm{p}$.

CABRAL, E. L.; BARBOSA, D. C. A.;

SIMABUKURO, E. A. Armazenamento e germinação de sementes de Tabebuia aurea (manso) Benth. \& Hook. f. ex. S. Moore. Acta Botanica Brasilica, v. 17, n. 4, p. 609-617, 2003.

FIGLIOLIA, M. B.; OLIVEIRA, E. C.; PIÑARODRIGUES, F. C. M. Análise de sementes. In: AGUIAR, I. B.; PIÑA-RODRIGUES, F. C. M.; FIGLIOLIA, M. B. (Ed.). Sementes florestais tropicais. Brasília, DF: ABRATES, 1993. p. 37-74.
GARCIA, Q. S.; DINIZ, I. S. S. Comportamento germinativo de três espécies de Vellozia da Serra do Cipó, MG. Acta Botanica Brasilica, v. 17, n. 4, p. 487-494, 2003.

GARCIA-HUIDOBRO, J.; MONTEITH, J. L.; SQUIRE, G. R. Time, temperature and germination of pearl millet (Pennisetum thyphoids S. \& H.). I. Constant temperature. Journal Experimental Botany, v. 33, n. 133 , p. 288-296, 1982a.

GARCIA-HUIDOBRO, J.; MONTEITH, J.L.; SQUIRE, G.R. Time, temperature and germination of pearl millet (Pennisetum thyphoids S. \& H.). II. Alternant temperature. Journal Experimental Botany, v. 33, n. 133, p. 297-302, 1982b.

GOMES, F. P. Curso de estatística experimental. Piracicaba: Escola Superior de Agricultura Luiz de Queiroz, 1982.430 p.

HORIBE, I. Y.; CARDOSO, V. J. M. Efeito do nitrato na germinação isotérmica de sementes de Brachiaria brizantha Stapf cv. Marandu.

Naturalia, v. 26, p. 175-189, 2001.

LABOURIAU, L.G.; PACHECO, A. On the frequency of isothermal temperature germination in seeds of Dolichos biflorus L. Plant \& Cell Physiology, v. 19, p. 507-512, 1978.

LORENZI, H. Árvores brasileiras: manual de identificação e cultivo de plantas arbóreas nativas do Brasil. Nova Odessa: Plantarum, 1992. 352 p.

MAYER, A. M. How do seed their environmental some biochemical aspects of the sensing of water potencial, light and temperature. Israel Journal of Botany, v. 35, p. 3-16, 1986.

MAYER, A. M.; POLJAKOFF-MAYBER, A. The germination of seeds. Oxford: Pergamon Press, 1989. 270 p.

NASCIMENTO, M. P. S. C. N.; OLIVEIRA, M. E. A. O. Quebra de dormência de sementes de quatro leguminosas arbóreas. Acta Botanica Brasilica, v. 13, n. 2, p. 115-236, 1999.

R. Árvore, Viçosa-MG, v.30, n.4, p.513-518, 2006 
POPINIGIS, F. Fisiologia da semente. Brasília: AGIPLAN, 1977. 207 p.

PROBERT, E. H. The role of temperature in germination ecophysiology. In: FENNER, M. The ecology of regeneration in plant communities. 2.ed. Wallingford: $\mathrm{Cab}$ International, 1993. p. 285-325.

RAMOS, M. B. P.; VARELA, V. P. Efeito da temperatura e do substrato sobre a germinação de sementes de visgueiro do igapó (Parkia discolor Benth) Leguminosae, Mimosoideae. Revista de Ciências Agrárias, n. 39, p. 123-133, 2003.
RIZZINI, C. T. Botânica econômica brasileira. 2.ed. Rio de Janeiro: Âmbito Cultural, 1995. 248 p.

SILVA, L. M. M.; MATOS, V. P. Quebra de dormência de sementes de mulungu (Erythrina velutina Willd.) e jucá (Caesalpinia ferrea Mart. ex Tul). Informativo ABRATES, v. 1, n. 4, p. 81,1991 .

VILLAGOMEZ, A. Y.; VILLASENOR, R. R.; SALINAS, M. J. R. Lineamento para el funcionamiento de um laboratorio de semillas. Mexico: INIA, 1979. 128 p. 